\section{Life's forms}

\author{
William R. Taylor and \\ N. Michael Green
}

Structure in Protein Chemistry. By Jack Kyte. Garland: 1995. Pp. 606. \$62.

"WHAT is the secret of life?" I asked. . . "Protein", the bartender declared. "They found out something about protein."

The storyteller in Kurt Vonnegut's novel Cat's Cradle, having posed the ultimate biological question, unfortunately did not pursue the bartender's perceptive answer. Instead, he continued to seek for Truth in L. B. Johnson's "Books of Bokonon", which, despite being a source of much wisdom, have very little to say about proteins and nothing at all about protein structure.

The encounter took place in the early 1960 s and the event to which the bartender refers is, obviously, the elucidation of the first globular protein structure by X-ray crystallography. But following the narrow path from the structure of myoglobin to the answer to the ultimate question requires more than simply contemplating the fruits of the crystallographer's trade for long hours on the computer screen: the modern molecular acolyte must also master the world of atoms and forces.

When every presentation of a protein structure in today's literature is a shiny sinuous sculpture, it is all too easy to forget chemistry and simply accept the view that proteins are made of multicoloured Play Doh. This growing misconception is seldom dispelled with any conviction in any of the relevant textbooks: most of them attempt to cover the whole of biochemistry and, in the limited space accorded to protein structure, they move quickly from the structure of the 20 amino acids, through secondary structure, to the more abstract representations of protein folds. Exceptions can be found in the more specialized volumes such as Principles of Protein Structure by G. E. Schulz and R. H. Schirmer (Springer, 1979) and the more recent and comprehensive Proteins: Structures and Molecular Properties by T. E. Creighton (2nd edn, W. H. Freeman, 1983).

To this limited selection of textbooks on protein structure, Jack Kyte has contributed a volume covering the whole range of structural levels (from atomic orbitals to protein assemblies) as well as most of the physico-chemical techniques required for the purification and characterization of proteins. Structure in Protein Chemistry is one of a pair of large volumes aimed at the advanced undergraduate upwards and would probably be best suited to someone entering research in the field, either at pre- or post-doctoral level. In the companion volume, Mechanism in Protein Structure (Garland, 1995), Kyte deals with mechanism, and so the 'structure' volume contains little or nothing about function, catalysis or allosteric effects - even the chapter on evolution is presented largely in terms of structure. It is no doubt intended that each volume should be able to stand alone, but there can't be many students who would want to study the symmetry of oligomeric proteins without making reference to allosteric interactions. Even with both volumes to hand, gaining the complete view would not be easy: surprisingly, the 'structure' volume contains no crossreferences to (or even mention of) the 'mechanism' volume.

Kyte aims to take the student back to fundamentals - "to develop in the student the ability to draw her own conclusions from only the experimental results". This goal explains the size and level of detail in the work and also the sometimes pedantic avoidance of the slightly loose terms in common usage. For example, 'structure', which is often applied to the three-dimensional representation of a protein, is replaced throughout the text by 'crystallographic molecular model' (or its NMR equivalent) and, similarly, 'Bragg spacings' is used where 'resolution' would be expected. This approach extends also to the representation of detailed stereochemistry in which all the lone-pair electrons are indicated, turning a molecule even as simple as $\mathrm{SO}_{4}$ into something more like a diagrammatic analysis of a snooker break. Undoubtedly, there are times when such exactness is required, but when applied so relentlessly, the flow of the text falters and even comprehension of some more difficult points is obscured. But if the student perseveres, he or she will arrive at a more accurate, and perhaps deeper, understanding of many of the topics.

Most modern general textbooks on proteins, such as Creighton's, use specially prepared figures that can be greatly enlivened by the use of colour, as in C.-I. Brändén and J. Tooze's Introduction to Protein Structure (Garland, 1991). In addition, the layout is often highly structured (with many short sections in a hierarchical order) making it easy to locate a section of interest and quickly find an answer to some specific point. Kyte's volume departs from this modern trend; the figures (apart from small organic structures) are almost all taken directly from the research literature and the sections can be long (nine pages on average). But with a comprehensive index and key words printed boldly in the text it is not too difficult to locate the relevant segment.

Despite some negative aspects (most of which annoy rather than mislead), the volume is a valuable and unique contribution to the literature on protein structure. In emphasizing experimental studies, it presents a coherent and detailed background to many 'methods' often glossed over (or omitted) elsewhere. One of the strongest aspects of the work is the extensive lists of references after each chapter, which provide access to the research literature not available since Schulz and Schirmer's volume. This will make the book particularly useful to research students who need to understand the subject in depth (or at least give an impression of doing so). Unfortunately, some of the reference lists are now out of date, with almost no coverage of developments since 1990. For example, only one NMR-based structure is discussed and there is little on mass spectrometry. More seriously, the section on microtubule assembly is ten years behind the times and there is almost nothing on computer methods for sequence modelling and structure prediction-indeed the corresponding sections Schulz and Schirmer's 1979 textbook still provide a better account.

Should we, then, cast aside our 14 Books of Bokonon in favour of one (or two) by Kyte? We would certainly learn more about protein structure and also quite a lot of chemistry (but not, alas, the structure of ice-IX). The important question though is how close this will take us to the secret of life. Somewhere between atoms (obviously dead) and cells (obviously alive) lies the key transition. In Chance and Necessity, Jacob Monod tells us that proteins are purposeful (equating them with Maxwell's Demons). As this is clearly a life-like property, where better to start our search than by acquiring a full and detailed knowledge of protein chemistry and structure?

William R. Taylor and N. Michael Green are in the Division of Mathematical Biology, National Institute for Medical Research, The Ridgeway, Mill Hill, London NW7 1AA, UK.

\section{Biochemistry textbooks}

New editions of two influential textbooks in biochemistry have just been published. The fourth edition of Biochemistry by Lubert Stryer (W. H. Freeman, £29.95) has been reorganized to accommodate new advances in recombinant DNA technology, protein chemistry and structural biology. There is a new chapter on protein folding and design. The second edition of Biochemistry by Donald Voet and Judith G. Voet (Wiley, \$76.95) also covers our new understanding of nucleic-acid and protein structure. It has an increased emphasis on human disease and makes extensive use of molecular biological techniques and molecular-graphics illustrations. 